\title{
USE OF ENVIRONMENTAL APPROACH TO INNOVATION-ORIENTED DEVELOPMENT OF INDUSTRIAL ENTERPRISES
}

\author{
Sergej Petrovich Baranenko, Mihail Nikolaevich Dudin, \\ Nikolaj Vasil'evich Ljasnikov and Konstantin Dmitrievich Busygin
}

Russian Academy of Entrepreneurship, UL, Radio d.14, 105005, Moscow, Russia

Received 2013-11-23; Revised 2013-12-04; Accepted 2013-12-19

\begin{abstract}
To investigate, identify and specify environmental factors influencing sustainable and competitive development of industrial enterprises which are the driver of growth of national economies. External and internal environmental factors are considered in the context of innovation potentialities of companies-and innovations are the key factors which provide sustainable development of business structures. World practice of sustainable development in regard to industrial enterprises and modern theoretical and empirical concepts are investigated which tie-up sustainable development of industrial enterprises to their innovation activity. The result of this study is limited practice-oriented concept of complex character which allows to conclude that the level of innovation activity of an industrial enterprise directly depends on the level of its functioning and development. Practical use of the concept of interrelation of the level of development of industrial enterprises with due regard to above-mentioned restrictions is perspective in terms of formation of new tools considered as optimal limited alternative to current managerial approaches which mainly are response to external environmental changes, while modern business conditions demand pro-activity.
\end{abstract}

Keywords: External Environment, Internal Environment, Industrial Enterprises, Innovations, Potential, Development, Foresight Designing, Road Mapping

\section{INTRODUCTION}

World business space is changing and these changes on the one hand are cardinal and radical but on the other hand are intrinsically necessary, being logical consequence of those changes which accompany transition from traditional economy to economy of knowledge and from traditional hierarchical society to information society. World community and economy turn into global network where geographical boundaries are of no significance for effective interaction (Sadovnichy et al., 2012). That is why innovative processes become more and more global and play more significant role in sustainable development of local, national socioeconomic systems and World-System as a whole.
Of course, in the nearest future and for the whole $21 \mathrm{st}$ century innovations will determine the success and competitiveness of separate industrial enterprises, their groups, clusters and industries. It is connected with the fact that society and economy crossed the break-point after which there is no return to traditional socioeconomic values and they need quality leap to new hightech order (Sapir et al., 2013).

In the framework of this new order knowledge becomes the main strategic resource of development, the man becomes main value as doer and generator of transformations of knowledge into innovations. Senior management of industrial enterprises must recognize that innovative activity, ability to accumulate and use one's own innovative potential, obtain by it direct or indirect economic benefits is the essence and main condition for Corresponding Author: Sergej Petrovich Baranenko, Russian Academy of Entrepreneurship, UL. Radio d.14, 105005, Moscow, Russia 
balanced growth and competitiveness for oncoming period (Pandiyan et al., 2011).

\section{MATERIALS AND METHODS}

Methodologically the article is aggregated data of content-analysis, data of socio-economic development of small and big socio-economic system obtained from open sources and investigated by economicstatistical methods.

\section{RESULTS}

Innovations changed the world's skin and made business create. Recent NOVA Innovation Competition 2012" (SG, 2013) which gathered innovative projects from more than 28 countries of the world showed that new entrepreneurial ideas can be created in different spheres: They range from production of ecologicallyharmless building materials and new energy-saving devices to development of new technologies of provision of the consumers with new kinds of services (building, touristic, entertainment, informational).

Results of this contest allow to say that entrepreneurial idea of modern times is looking for new ways of making products and services as well as their promotion in the market; and these ways are first of all are based on understanding of the main idea of sustainable development of World-System: Rational functioning, based on reasonable consumption of resources, safe and harmonious activity of present and future generations.

Aspiration to use innovations for sustainable development of enterprises and organizations both of real and financial sector of economy becomes a benchmark in innovation environment and this indicates that readiness of industrial sector for changes to provide sustainable and strategically competitive development is constantly increasing. Therefore the key role of innovation, as well as importance of the role of industry in creation factors of national economy's growth do not raise any doubts. Readiness for changes including changes caused by innovatics, as a rule, is connected with management of internal environment of industrial enterprises.

But development of innovative capabilities of modern industrial enterprises is to no less extent is determined by external environment. Here it is necessary to note that internal environment of industrial enterprises (its organizational and managerial space) is formed at the expense of necessary resources, technologies and capital. In its turn external environment (environment of functioning and development) is formed by the needs, possibilities and alternatives.

By internal environment of industrial enterprises we understand located by organizational boundaries combination of interrelated and inter-dependable elements, socially and economically systematized, whose management provides sustainable development of this industrial structure and its balanced growth. By external environment of industrial enterprises we understand a system combination of institutional, infrastructural, economic-technical, social-political and scientifictechnological factors and conditions ascertaining the space of activity of this industrial structure, as well as directly or indirectly influencing its current functioning, sustainable development and balanced growth in long term (strategically) (Dudin, 2012).

We are going to consider some factors of external environment in the context of provision of innovationoriented development of industrial enterprises in more detail. First of all it is necessary to pay attention to the fact that innovative development of industrial enterprises is determined by 2 main external environment factors:

- Firstly, it is general innovative-investment and scientific-technological climate which has formed in national economy, it means sufficiency and accessibility of fundamental, applied and technological base intended for support of innovation activity of industrial sector

- Secondly, completely formed type of national economy and principal readiness and ability for performance of innovation activity in general and implementation of industrial innovations in particular

First aspect is connected with recognition of key role of innovation as main driving force of socioeconomic development of the state. Besides that a combination of effective measures intended for formation of developed economic space of innovatics is necessary. This means not only direct (in the form of innovations) or indirect (in the form of different (tax) privileges) financial support, investors' moral motivation support (support of their aspiration to invest into venture projects) is of most importance.

Scientific and financial support of innovative processes provided on governmental level by optimal scientific-technological and innovative policy is 2 reflection of the same phenomenon. Quality (readiness) of external environment in which industrial structure is functioning and developing by means of innovation activity is in the same time the 
key condition. It is worth mentioning that the quality of external environment in the context of support for innovative activity of industrial sector and the whole national economy varies greatly from a country to country. In order to determine the condition of external environment and its quality in the part of provision of scientific, financial, state and other kinds of support of innovative processes they usually use aggregated indicators, including several groups of quality and quantity values which determine the level of innovatics development in a country.

In particular, Global innovation index, developed by WIPO, Corneal University and Business school INSEAD aggregates more than 80 single indicators. Global innovation index show the level of innovative potential of national socio-economic system and its ability (including abilities of separate enterpr) for sustainable development and balance socio-economic growth.

In the Table 1 above the dynamics of national scores of GII is shown for the last 3 years on the Top-10 countries. We can conclude that these countries never changed for 3 years (except for Germany which downgraded in 2013 to 15 th position in the ranking).

Secondly, all the countries from Top-10 are the most developed socially and economically. It must be mentioned that in 2012-2013 Russian Federation demonstrates nonconstant increasing dynamics in ranking. On the contrary, in 2013 the position of Russian Federation in the ranking downgraded from 51 to 62nd place (Fig. 1).

On one hand ranking of Russian Federation in 2013 downgraded only for $1,8 \%$ in comparison with 2012 and increased for 5\% in comparison with 2011. On the other hand downgrading of RF demonstrates that additional measures are necessary for increase in innovation activity in the economy and here the main condition for growth of innovation activity is transition from resource- oriented and effect-oriented economy to innovationoriented economy which is:

- Characterized by values-based competition by means of use of complex method of development, production of goods, works, services

- Based on knowledge which is regarded as global strategical factor of competitiveness

Transition to the new type of economy and economical relations must be accompanied by development of innovation activity of population and formation of potential entrepreneurial capabilities to use innovations as key potential of development. GEM experts point out that formation and development of entrepreneurship in general and innovative-active entrepreneurship in particular is possible when 3 main conditions exist in this new economy (7):

- Condition \#1 Positive public attitude to entrepreneurship and availability of reserve of innovative abilities in the society which allow to explore opened opportunities in external environment

- Condition \#2 Availability of relatively high entrepreneurial activity-it means readiness of individuals or their groups to initiate formation of new industrial structures in traditional and innovation segment of business

- Condition \#3 Availability of entrepreneurs' aspirations for sustainable development-ability to identify signals from external environment about changes in business-situation and transform these changes into economic or non-economic benefits for industrial structure using innovatics

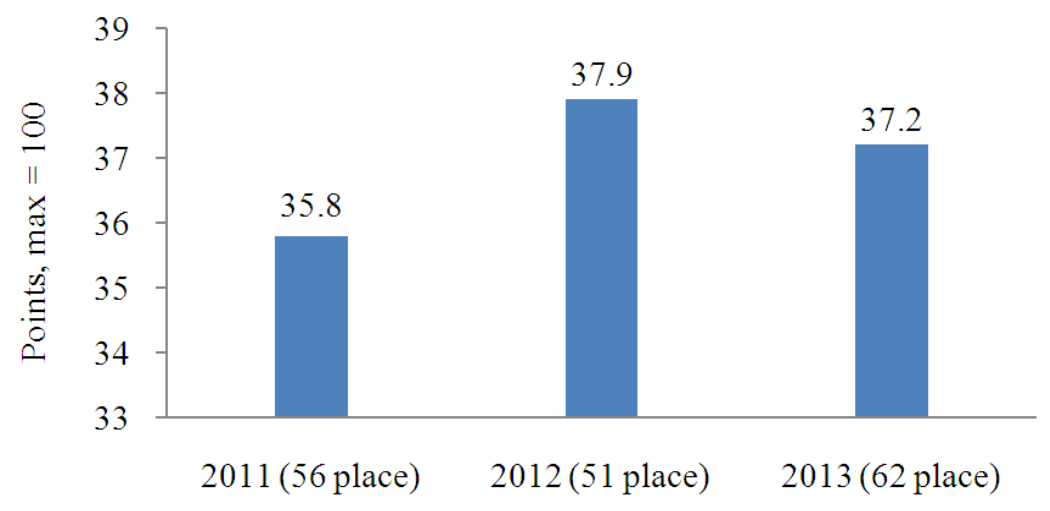

Fig. 1. Dynamics of RF position in GII ranking in 2011-2013 (6) 
Table 1. Dynamics of GII values in 2011-2012 in the countries of Top-10 (6)

\begin{tabular}{|c|c|c|c|c|c|}
\hline \multicolumn{2}{|l|}{2011} & \multicolumn{2}{|l|}{2012} & \multicolumn{2}{|l|}{2013} \\
\hline Country & Score & Country & Score & Country & Score \\
\hline Switzerland & 63,82 & Switzerland & 68,2 & Switzerland & 66,6 \\
\hline Sweden & 62,12 & Sweden & 64,8 & Sweden & 61,4 \\
\hline Singapore & 59,64 & Singapore & 63,5 & Great Britain & 61,2 \\
\hline Hong Kong & 58,8 & Finland & 61,8 & Holland & 61,1 \\
\hline Finland & 57,50 & Great Britain & 61,2 & The USA & 60,3 \\
\hline Germany & 56,96 & Holland & 60,5 & Finland & 59,5 \\
\hline The USA & 56,57 & Denmark & 59,9 & Hong Kong & 59,4 \\
\hline Canada & 56,33 & Hong Kong & 58,7 & Singapore & 59,4 \\
\hline Holland & 56,31 & Ireland & 58,7 & Denmark & 58,3 \\
\hline Great Britain & 55,96 & The USA & 58,7 & Ireland & 58,3 \\
\hline
\end{tabular}

\section{DISCUSSION}

Russia as a country with transformational type of economy must create conditions for increase in entrepreneurial activity of population, including industrial sector. But even today the level of entrepreneurial activity in Russia is rather high-for every 10000 people 170 people are newly-registered entrepreneurs. But the level of annual leaving is much lower-about 110 per 10 000. It is worth mentioning that first indicator-(the level of developing entrepreneurial activity of population in Russia) is similar to the indicators of such countries as Italy and Belgium, second (level of annual leaving entrepreneurial business in Russia) is similar to Japan and Italy whose economy is innovation-oriented (Ivanter, 2007).

Therefore it is obvious that for innovative development of industrial enterprises, on the one hand, objective state of external environment, factors, conditions and incentives formed in it is of key importance. On the other hand, subjective readiness and ability of entrepreneurs for long term functioning and development in the activity market is not of less importance (Chantarasombat and Singkeaw, 2012). Here the key element is not only internal aspiration for longterm development, but the mentioned above ability to correctly identify signals from external environment which outline areas of focus and form limitations of business activity of industrial structures in external environment (Koshy et al., 2011). Long time ago, in the first part of 20th century I. Ansoff when he was talking in about strategic development of companies pointed out that with increasing force of external environment signals reaction to them becomes more determined (non-probabilistic) (Chantarasombat and Singkeaw, 2012).

Table 2 shows the increasing scale of external environmental signals and measures which must be taken to guarantee sustainable and competitive development of industrial enterprises. It is clear from Table 2 that while managing functioning and development of industrial enterprises you must realize that strength of signals from external environmental always increases.

This means that if at the initial stages identification of the external environment signals, when threats, opportunities are only being recognized, response measures are focused in 2 planes: Current and strategic (perspective) decisions. On the contrary if the signals were not identified in time and complex of current and perspective decisions appropriate to that situation was not implemented, then, at stages when threats and opportunities are completely specified and they are influencing activity of entrepreneurial structure the adopted measures are completely of situational character.

Situational reaction to changes in the external environment obviously increases the level of entrepreneurial risks and taking into consideration that innovatics, by its nature, is a zone of increased risks, negative environmental effects are characterized by synergy (multiplication) (Hirooka, 2006). In order to prevent such situation industrial structures' leaders must first of all change the type of management from reactive to pro-reactive (do not react to already happened changes but foresee future changes). Secondly, pro-active type of management of industrial structures activity needs special tools. 
Table 2. Managerial measures implemented for sustainable development of industrial enterprises while identifying signals from external environmental (Table is developed by the author)

Strength of signals and following

changes in external environmental

changes in externalenvironmental

Managerial measures and actions

I. Identification of trend in changes, evaluation of changes impact's strength

II. Measures intended for reduction of strategic sensitivity

III. Measures intended for increase in sustainable development and

competitiveness of the enterprises

Zone of current urgent solutions

I. Dangers and opportunities are recognized

II. Sources of dangers and opportunities become understandable (clear)

III. Size of dangers or opportunities is specified and their influence is defined
Zone of urgent perspective solutions intended for development of an enterprise

Zone of current urgent solutions which must support functioning of an enterprise Zone of urgent perspective solutions intended for development of an enterprise Zone of current urgent solutions intended for elimination of negative effects of external environmental factors' impact, support of current functioning, adoption of program measures for optimization of enterprise development
It is worth noting that by now theory and practice of industrial enterprises management has accumulated many successful tools intended for formation of relatively precise forecasts and scenarios of external environment changes, but it should be mentioned that all available approaches are to a great extent probabilistic. In practice it is very difficult to guarantee full feasibility of forecast or scenario because of latent factors which can never be identified at a certain stage of decisionmaking in regard to measures intended for sustainable development of industrial structure.

Two scenario technologies of constructing future industrial enterprise can be emphasized-these are foresight technologies and technologies of road mapping (Dudin et al., 2013).

Foresight (technological or innovative foresight designing) forms general vision of the future of entrepreneurial structure or its framework of development and functioning in changing conditions of external environment. Road mapping covers 3 most significant aspects of functioning and development of industrial structure:

- Firstly, it is market and consumers' demand in the market. It is well-known that consumers' demand in the market of industrial enterprises activity is changing under the influence of objective and subjective factors, but main factor which influences demand's changes is the level of consumers' income and their ability to perceive new products

Having evaluated consumers' demand and its changes caused by 2 main factors industrial structure can compare appropriateness of its market offer and its transformation with market demand and its transformation. This will allow to identify level of market asymmetry:

- Secondly, its the industrial structure itself, its mission, targets of being in market and the tasks of functioning and development. The targets of industrial structure activity must be compared with targets of consumers' segment targets and competitors' targets. This comparison will discover not only threats and opportunities but will allow find out not occupied niches or niches which are just being formed. These opportunities must be identified as early as possible-this will influence long-term competitive success of a industrial structure and its ability to lead in the market

- Thirdly, these are technologies which industrial structure uses and will use to provide its sustainable development in external environment

There are 2 types of technologies: Product-oriented and process-oriented, for industrial enterprises having significant potential of development, the problem of choice of proper type is not critical (both types are used). Entrepreneurial structures which have limited development potential must choose the most effective, in the part of obtaining direct and indirect economic benefits, technologies.

In our opinion, road map and innovation foresight are 2 approaches to simulation of current functioning and sustainable development of industrial structure in future which have the same purpose. This purpose is choice and detailed working-out of the most optimal path of company's evolution from present to future taking into consideration its current potential, capabilities and open or being opened opportunities of external environment. 
Foresight-designing and road-mapping must provide for 2 basic variants of forecasting and constructing of future of industrial enterprises. These are slow-response development and innovative breakthrough. Transition from one state to another-to be more exact-the speed, duration and other quality and quantity characteristics of transition-will depend on the transformation potential accumulated by industrial structure and dynamics and changes of external environment.

Here foresight-designing and road-mapping must identify precisely the effect which is planned to obtain by implementation of plans formed by means of these tools. Taking into consideration that innovatics, as any complex phenomenon, has system-synergy foundation it is necessary to identify the following types of effects obtained from sustainable development of industrial enterprises provided thanks to foresightdesigning and road-mapping:

- Economic effect determines profitability of industrial structure activity when innovationoriented type of development is realized

- High-tech effect determines the appropriateness and "living ability" of technologies, chosen for innovationoriented development of industrial structure

- Social effect allows to reason the benefits which are directly or indirectly obtained by the society from innovation activity of industrial structure and its sustainable development

- Ecological effect determines harmlessness of innovations for environment and their potential ability to minimize anthropogenic load caused by transition of industrial structure to innovation type of development

\section{CONCLUSION}

Summarizing everything which was said in this article we should notice that innovative development of modern industrial structure is determined by some combination of external and internal environmental factors.

Internal factors must be analyzed in the context of the readiness and ability of industrial enterprises for innovation-oriented development which is possible with pro-active management-management directed to investigation and formation of the future of industrial structure. External factors should be analyzed in the context of opening environmental opportunities which allow industrial structure to realize accumulated innovation potential for provision of sustainable development and obtaining additional economic benefits inaccessible to the competitors.
Modern managerial tools which are necessary for sustainable development of industrial enterprises in innovative direction are presented as combination of scenario technologies (foresight-designing and roadmapping). They differ from traditional procedures of planning and forecasting by ability to construct future of industrial structure-use open and opening opportunitiesand provide by it the choice of best path of innovationoriented development.

\section{REFERENCES}

Chantarasombat, C. and T. Singkeaw, 2012. Quality business service provider in community enterprise. J. Soc. Sci., 8: 258-262. DOI: 10.3844/jssp.2012.258.262

Dudin, M., 2012. A systematic approach to determining the modes of interaction of large and small businesses. Eur. J. Econ. Stud., 2: 84-87.

Dudin, M.N., N. Lyasnikov, S.V. Pankov and E.N. Sepiashvili, 2013. Innovative foresight as a tool of competitive development of entrepreneurial structures. World Applied Sci. J., 26: 1086-1089. DOI: 10.5829/idosi.wasj.2013.26.08.13550

Hirooka, M., 2006. Innovation Dynamism and Economic Growth: A Nonlinear Perspective. 1st Edn., Edward Elgar Publishing, Cheltenham, ISBN-10: 1845428862, pp: 448.

Ivanter, V., 2007. Long-term forecast of Russian economic development for 2007-2030: Possible options. Stud. Russian Econ. Dev., 18: 565-591. DOI: 10.1134/S1075700707060019

Koshy, K.C., A. Koroi, N. Netaf and C. Koya-Vaka'uta, 2011. Integrating sustainability into teaching and research at the university of the south pacific to enhance capacity for the sustainable development of pacific island countries. J. Soc. Sci., 7: 6-12. DOI: 10.3844/jssp.2011.6.12

Pandiyan, P., A. Murugesan, T. Vidhyadevi, S. Dineshkirupha and M. Pulikesi et al., 2011. A decision making tool for hazardous waste landfill site selection. Am. J. Environ. Sci., 7: 119-124. DOI: 10.3844/ajessp.2011.119.124

Sadovnichy, V., A. Akaev, A. Korotaev and S. Malkov, 2012. Simulation and foresighting world dynamics. Moscow.

Sapir, Z., V. Ivanter, A. Nekipelov and A. Kuvaldin, 2013. Russian transformation: After 20 years. Moscow.

SG, 2013. NOVA Innovation Competition 2012. SaintGobain. 